\title{
Urban Kindergarten Parents' Beliefs about Exposure to Music and Art and Early Learning
}

\author{
Roseanne L. Flores \\ Hunter College of the City University of New York, New York, USA \\ Email: rflores@hunter.cuny.edu
}

How to cite this paper: Flores, R. L. (2020). Urban Kindergarten Parents' Beliefs about Exposure to Music and Art and Early Learning. Creative Education, 11, 885-897. https://doi.org/10.4236/ce.2020.116064

Received: April 19, 2020

Accepted: June 25, 2020

Published: June 28, 2020

Copyright $\odot 2020$ by author(s) and Scientific Research Publishing Inc. This work is licensed under the Creative Commons Attribution International License (CC BY 4.0).

http://creativecommons.org/licenses/by/4.0/ (c) (i) Open Access

\begin{abstract}
Previous research over the past decade has demonstrated a strong relationship between children's exposure to the arts and educational outcomes. The purpose of the present study was to examine low-income urban kindergarten parents' beliefs concerning the relationship between music and art young children's school performance, behavior, and participation in the arts. Parents of 215 children attending kindergarten in one of two Title 1 public schools in New York City completed a survey concerning their beliefs about the effects of music or art on their children's learning. Of the 215 parents, 73 ( $45.2 \%$ with children receiving music) and ( $16.4 \%$ with children receiving art) completed the survey. The results revealed that parents in both groups perceived music and art as influencing academic skills, with all parents seeing improvement in children's attention to detail. For children who received music training, parents observed an improvement in their children's listening skills and pattern recognition. Parents' perceived the most significant improvement in their ability to recognize shapes for children who received art training. Findings from this study suggest the need for encouraging parents from low-income communities to support and advocate for their children to have exposure to the arts during the early childhood years.
\end{abstract}

\section{Keywords}

Parental Beliefs, Young Children, Music, Art, Academic Skills, Early Childhood, Early Education

\section{Introduction}

Over the past twenty-five years, there has been a surge in research examining the effects of music on the academic achievement (Rauscher \& Zupan, 2000), cognitive development (Rauscher, 2003), and the behavior of children from mixed socio-economic backgrounds (Hallam \& Price, 1998; Kirschner, \& To- 
masello, 2010; BPS, 2013). Although the findings from this research have not always been consistent, there has been much support for the proposition that music is positively related to academic achievement, cognitive functioning, and behavioral changes. That said, while the outcomes have been positive for middle-class children few studies to date have examined the effects of music on low-income children's academic achievement and behavior (Brown \& Sax, 2013; Brown, Benedett, \& Armistead, 2010; Brown, Garnett, Velazquez-Martin, \& Mellor, 2018). Moreover, even fewer studies have examined the relationship between the arts broadly defined and children's school readiness and overall development (National Endowment of the Arts, 2011, 2015). Furthermore, even fewer studies have examined parents' beliefs concerning the effect of music and the arts on academic achievement (Kantner \& Hoffman, 1992; Custodero, Rebello, \& Xin, 2002). To address this issue, the present research, which was part of a larger research project (Flores, 2006), examined low-income parents' beliefs about the relationship between music and art and their children's school performance. The basic premise of the research reported in this paper was that parents from low-income communities, much like their middle-class peers, would want their children to be exposed to music and the arts in order to provide them with the additional cultural capital necessary for future success. However, unlike the children of middle-class parents, for whom exposure to music and the arts is often a part of their lives, it was also proposed that parents from low-income communities might also want their children to be exposed to music and the arts not only for their primary benefits, i.e. to provide children with an appreciation for culture, but also for their secondary benefits which might include the enhancement of listening skills, an increase in attention to detail, and an enhancement of language and literary skills, skills which could be considered additional by-products of exposure to the arts.

\section{Overview of the Literature}

\subsection{The Arts and Early Childhood Education}

The arts have been defined as including music (which includes singing and dance), visual art (which includes drawing and painting), and drama (which includes theatre). Recent reviews of the literature have examined the benefits of exposure to the arts during early childhood and their positive effect on developmental outcomes (National Endowment of the Arts, 2011, 2015). In general, the findings have suggested that exposure to the arts can enhance cognitive and learning skills, particularly for those children most at risk for poor developmental outcomes (National Endowment of the Arts, 2011). That said, to date, only a small number of studies have examined the effect of the visual arts on children's school readiness skills (Brown, Benedett, \& Armistead, 2010; Brown \& Sax, 2013; Brown et al., 2018). Results from this research have suggested that children who attend an arts program have better receptive vocabulary than children who do not attend such a program (Brown, Benedett, \& Armistead, 2010) and have superior 
positive emotions (Brown \& Sax, 2013). That said, while these results are promising, there is still a lack of research in this area, with the majority of studies examining the effect of music on developmental outcomes and school achievement. The next section will review the literature on music and learning in the early years.

\subsection{Music and Learning and Developmental Outcomes}

Music has long been thought to be associated with positive effects on brain development and cognitive functioning (Hallam, 2010). Rauscher, Robinson, \& Jens (1998) demonstrated that when rats were exposed to complex music, they performed better and faster on a spatial task than rats who were exposed to simple forms of music, white noise, or silence. These findings suggested that the modification of the environment had a significant effect on cognitive functioning. The transfer of such findings from animal research to human development has significant implications for education.

In addition to the above findings, earlier research by Hurwitz, Wolff, Bortnick, \& Kokas (1975) examined the effect of music training on first-grade children's reading performance. In this study, the experimental group was exposed to music training, and the control group received no specialized training. The authors found that children who received music training scored significantly better on reading tests than those who did not receive the training. Moreover, Lamb and Gregory (1993) found a relationship between pitch discrimination and phonemic awareness in first-grade children. Their results demonstrated that children who received music training performed better on tests assessing phonemic awareness than their peers who did not receive such training.

Moreover, Rauscher and her colleagues $(1994,2000)$, in their work with young children, found that exposure to keyboard lessons or listening to classical music was causally related to spatial-temporal reasoning.

In addition, to the effect that music appears to have on musical and spatial ability Vaughn (2000) in a meta-analysis of 25 studies found that people who either received private music training or were exposed to a music curriculum performed better on math tasks than individuals who were not exposed to music.

Building upon findings from the previous research Costa-Giomi (2004) followed 117 fourth grade students who participated in music instruction over three years. Children in the experimental group received individual piano lessons weekly over three years. All children in this group practiced on an acoustic piano at home. Children in the control group received no music training. All children were administered tests to assess self-esteem, academic achievement, cognitive skills, musical abilities, and motor skills. The results of the study demonstrated that there were no significant differences between the groups on academic achievement; however, music training was positively related to musical skills and self-esteem.

In addition to the positive effects that have been shown between exposure to music and academic achievement, Hallam \& Price (1998) also found that pro- 
viding background music during classroom activities had a positive effect on the behavior of children with emotional and behavioral difficulties.

Beliefs about the Effects of Music on Children's Development

Although there has been much research demonstrating that early exposure to music can lead to positive changes in cognitive development, academic achievement, and behavior few studies have examined parents' beliefs concerning the relationship between exposure to the arts on children's overall development. That said, a small number of studies have shown that parents who value the arts for their own sake have children who spend more time practicing their instruments and enjoy music more (Dai \& Schader, 2002).

In an attempt to address the gap in the research Custodero, Rebello, \& Xin (2002) administered a survey to a sample of parents from New York, California, and the Midwest containing questions about parents' general attitudes and beliefs about music and its effect on infants. The majority of the participants were female, white, and educated. Overall they found that the majority of parents exposed their infants to music every day and made a conscious effort to introduce their infant to music in utero. However, although parents made an effort to expose their children to music, they also reported listening to music that was different from what they felt was appropriate for their children. Moreover, when asked if they thought classical music made their children smarter, parents were not as definitive in their convictions.

In short, although middle-class parents introduced their children to music early on, the belief in the connection between listening to classical music and intelligence was not widespread. These findings, although important, address the views of well educated middle-class parents concerning the relationship of music to young children's intellectual and academic abilities and therefore, cannot be generalized to all parents. Moreover, the research only addresses parents' beliefs about exposure to music and not all of the arts.

Thus to address the gap in the research and build upon previous findings the purpose of the present study was to examine the beliefs of the parent's from low-income communities about the relationship between exposure to music and art (which included drawing and painting) and their children's 1) increased interest in participating in the arts, 2) their school performance, and 3) a change in behavior.

\section{Methods}

The research reported in this paper was part of a larger research project using a mixed-methods design that was conducted to examine the effect of music and art instruction on young children's academic achievement (Flores, 2006). In that study, children attending kindergarten in an urban public school either received music training or art training from teachers certified in either music or art. The research reported in this is based on survey data collected from parents about their beliefs concerning the relationship between music and young children's in- 
terest in participating in the arts, school performance, and a change in behavior.

\section{Participants}

The participants for this study were the parents of 73 kindergarten children (39 female, 33 male, 1 with missing information about gender) ages 5-6, mean age 5.3 years, who at the time the survey was conducted were attending one of two Title 1 public schools in New York City. Both schools were in the same district and served a predominantly Hispanic population.

\section{Survey}

The survey consisted of 25 items constructed by the author. The questions assessed parent's views about whether or not they perceived that involvement in music or an art program effected their children's academic skills, desire to learn, and behavior (See Table 1 for a list of the questions).

Table 1. Parent music and art survey.

1. Is your child? Mal Female

2. What is your relationship to the child?

3. List the racial and ethnic categories, which you would consider yourself to be?

4. What language is usually spoken in your home?

5. Is English your native language?

6. What is (are) the primary language(s) that your child uses at home?

7. How often do you help your child with homework?

8. What type of homework do you help your child with?

9. Is your child involved in any type of activities outside of school?

10. Is your child involved in a music program in school?

11. Do you listen to music at home?

12. Is your child involved in a musical activity outside of school?

13. Does your child play an instrument?

14. What instrument does your child play?

15. *Answered only if question 12 was answered.

Do you have an instrument at home?

16. How often does your child practice their instrument?

17. How much time does your child spend practicing their instrument?

18. Is your child involved in an art program in school?

19. Is your child involved in an art activity outside of school?

20. If your child is participating in a musical activity, have you noticed any improvement in their academic skills? If yes check all that apply.

21. If your child is participating in an art activity, have you noticed any improvement in their academic skills? If yes check all that apply.

22. If your child is participating in a musical activity has it increased their desire to learn? Check all that apply.

23. If your child is participating in an art activity has it increased their desire to learn? Check all that apply.

24. Have you noticed any change in your child's behavior since they have begun participating in an art/music activity? If yes, in what areas have you noticed the change. Check all that apply

25. Do you think music/art are important to your child's academic achievement? Please explain. 


\section{Procedure}

Over the school year (October through May), all children in the study either received music or art training two times a week for 45 minutes from either a specialized music teacher or art teacher, before the administration of the parental survey. At the end of the school year, surveys were given to all parents of the children who participated in either the music or art training program. A total of 215 surveys were distributed, with 73 being completed and returned.

\section{Results}

\section{Analysis of the Survey}

The results are presented in four sections: 1) family characteristics; 2) children's music and art exposure; 3) parental perceptions about the arts; and 4) parental qualitative explanations about the importance of the arts and academic achievement. To examine possible differences between the music and art groups chi-square analyses were conducted to assess the categorical data from the survey. In addition, Spearman rho correlation coefficients were also calculated.

\subsection{Family Characteristics}

Of the parents completing the survey, the majority were mothers $(75.3 \%)$, with the largest ethnic group represented being of Hispanic origin ( 75.3\%), and the primary language spoken at home being Spanish (37\%). In addition, of the parents completing the survey (78.1\%) reported helping their children with their homework nearly every day. Moreover, parents reported primarily helping their children with homework in reading, writing, and with art projects (26\%). See Table 2 for overall family characteristics.

\subsection{Children's Music and Art Exposure}

Of the parents who had children who participated in the music program, the most substantial number $13.7 \%$ reported that their children enjoyed listening to music. The next largest number of parents reported that going to the movies and reading $6.8 \%$, or participating in some combination of reading, going to the movies, and listening to music $6.8 \%$ were activities that their children enjoyed. Of the 27 parents who reported that their child played an instrument, the most substantial number $24.7 \%$ reported that their child played the piano. Only $19.2 \%$ of parents reported having an instrument in the home. In addition, $17.8 \%$ of the parents' who had children participating in the music program reported that their children were involved in a musically affiliated activity outside of school. The type of activity reported most frequently was dance.

A Spearman rho correlation coefficient was calculated in order to assess the relationship between how often the child spent practicing an instrument during the week and the amount of time devoted to playing the instrument every day. A moderate correlation was found (rho $(71)=0.498, p<0.01$ ), indicating a significant relationship between the two variables. 
Table 2. Family Characteristics $(\mathrm{N}=73)$.

\begin{tabular}{|c|c|c|}
\hline Characteristics: & $\mathbf{N}$ & $\%$ \\
\hline \multicolumn{3}{|l|}{ Gender of Child } \\
\hline Male & 33 & 45.2 \\
\hline Female & 39 & 53.4 \\
\hline Missing & 1 & 1.4 \\
\hline \multicolumn{3}{|l|}{ Age of Child (Years) } \\
\hline $5.0-5.5$ & 6 & 8.2 \\
\hline $5.6-6.0$ & 32 & 43.8 \\
\hline $6.1-6.5$ & 26 & 35.5 \\
\hline No information available & 8 & 12.4 \\
\hline \multicolumn{3}{|l|}{ Respondents Relationship Child } \\
\hline Mother & 55 & 75.3 \\
\hline Father & 10 & 13.7 \\
\hline Mother/Father & 7 & 9.6 \\
\hline No Response & 1 & 1.4 \\
\hline \multicolumn{3}{|l|}{ Race \& Ethnicity } \\
\hline Asian & 15 & 20.5 \\
\hline Spanish/Hispanic & 55 & 75.3 \\
\hline Other & 1 & 1.4 \\
\hline No Response & 2 & 2.7 \\
\hline \multicolumn{3}{|l|}{ Language spoken at home } \\
\hline English & 3 & 4.1 \\
\hline Spanish & 27 & 37.0 \\
\hline English/Spanish & 26 & 35.6 \\
\hline Chinese & 4 & 5.5 \\
\hline Korean & 1 & 1.4 \\
\hline Bangela/Bangla & 1 & 1.4 \\
\hline Punjabi & 1 & 1.4 \\
\hline Urdu & 2 & 2.7 \\
\hline Bengali & 1 & 1.4 \\
\hline English \& Bangela & 1 & 1.4 \\
\hline English \& Tagalog & 1 & 1.4 \\
\hline English \& Korean & 1 & 1.4 \\
\hline English \& Mandarin/Cantonese & 4 & 5.5 \\
\hline \multicolumn{3}{|l|}{ Provision of Homework Help } \\
\hline Nearly every day & 57 & 78.1 \\
\hline One or two times per week & 6 & 8.2 \\
\hline Not more than once a week & 0 & 0 \\
\hline Hardly ever & 8 & 11.0 \\
\hline No Response & 2 & 2.7 \\
\hline \multicolumn{3}{|l|}{ Type of Homework Help Provided } \\
\hline Reading & 6 & 8.2 \\
\hline Writing & 5 & 6.8 \\
\hline Mathematics & 3 & 4.1 \\
\hline Music Projects & 1 & 1.4 \\
\hline Reading and Writing & 13 & 17.8 \\
\hline
\end{tabular}




\section{Continued}

\begin{tabular}{ccc}
\hline Reading and Mathematics & 1 & 1.4 \\
Writing and Mathematics & 4 & 5.5 \\
Reading, Writing and Mathematics & 19 & 26.0 \\
Reading, Writing and Art Projects & 1 & 1.4 \\
Reading, Writing, Math and Art Projects & 3 & 4.1 \\
Reading, Writing, Math and Music Projects & 1 & 1.4 \\
Reading, Writing, Math and Science & 1 & 1.4 \\
Reading, Writing, Math, Art, and Music & 2 & 2.7 \\
Reading, Writing, Math, Art and Science & 4 & 5.5 \\
Reading, Writing and Science & 1 & 1.4 \\
All Subjects & 5 & 6.8 \\
No Response & 2 & 2.7
\end{tabular}

Of the 33 parents who reported their children being involved in the art training class, $11 \%$ noticed that their child demonstrated an increased interest in drawing and painting, and $8.2 \%$ noticed an increased interest in reading. Only $16.4 \%$ of parents reported that their children were involved in an art activity outside of school. Types of activity included drawing and painting.

To examine possible group differences within the art group chi-square tests were computed. No significant group differences were found for the following variables: help with homework, listening to music, and having an instrument in the home.

\subsection{The Relationship of Music and Art to Academic Achievement}

Of the 73 parents completing the survey, $45.2 \%$ reported having children in the music class, and $16.4 \%$ reported having children in the art program, with the parents of 7 children not responding.

Of the parents who had children who participated in the music program, only $30.1 \%$ viewed music as having improved their children's academic skills, 34.2\% did not see a difference, and $35.6 \%$ did not respond. For parents who reported seeing an improvement, the most considerable improvement was said to take place in listening skills, reading and listening, attention to details, and pattern recognition. Of the children who participated in a musical activity, several parents $15.1 \%$ reported an increased desire only to learn music or to learn music and dance $9.6 \%$, with some parents reporting an increase in their children's desire to read, participate in art, write and learn mathematics.

Two separate chi-square tests of independence were calculated comparing the frequency of children playing an instrument, and participating in music activities outside of school, with their parents' perception of academic achievement. A significant interaction was found $X^{2}(4)=14.658 p<0.005$, with the parents of children who played an instrument reporting an improvement in academics. No significant differences were found for participation in outside activities.

Of the parents who had children who participated in the art training program, 
$34.2 \%$ reported seeing an improvement in academic achievement, $27.4 \%$ reported no improvement, and $38.4 \%$ did not respond. The most significant improvements reported by parents for this group were in the areas of attention to details and shape recognition, and in areas that involved reading, writing, recognizing patterns and shapes, listening, and mathematics.

Furthermore, of the children who participated in the art training classes, parents reported an increased interest in music, art, and a combination of music, art, reading, science, mathematics, and writing.

Two separate chi-square tests of independence were calculated comparing the frequency of children's participation in an art class as well as their involvement in activities outside of school with their parents' perceptions of academic achievement. A significant interaction was found $X^{2}(4)=24.19 p<0.001$ with the majority of parents who had children who participated in art class perceiving their children to have performed better academically. Moreover, a significant interaction was found $X^{2}(4)=28.281 p<0.001$ with more parents observing that their children did not do better academically when they participated in art activities outside of school.

\subsection{The Relationship of Music and Art to Behavioral Change}

Regardless of whether their child was enrolled in a music or art class, $42.5 \%$ of the parents reported that they noticed positive changes in behavior. For example, parents reported that they felt their children paid more attention and listened better, cooperated more with children and adults, and had more respect for their instruments.

Two separate chi-square tests of independence were calculated comparing the frequency of music and art to parents' perceptions of positive behavioral changes. A significant interaction was found $X^{2}(4)=10.077 p<0.039$ with parents reporting that children who participated in music exhibited more positive behavioral changes. Moreover, a significant interaction was also found $X^{2}(4)=$ $14.350 p<0.006$ for the parents of children who participated in art with those parents reporting that their children exhibited more positive behavior.

\subsection{Parental Explanations about the Importance of the Arts and Academic Achievement}

In addition to the questions mentioned above, parents were also asked to explain whether they believed music and art were important to their children's academic achievement. In general, parents said that listening to music helped their children's brains to develop, gave them another way to express themselves, helped them with their listening skills, and was essential to academic achievement. For example, one parent said, "I really think that music and art are very important to my child's academic achievement. Because I believe that music and art can broaden their knowledge and ... help them to excel academically in school." Moreover, parents reported that they felt music helped their children with pat- 
tern recognition and motivated them by giving them an incentive to get up and go to school in the morning and participate in fun activities. For example, one parent stated that their child "learned to read music and play the keyboard ... opening up an interest in music that he did not have before participating in the program". Finally, others felt that art helped their children to pay more attention to detail.

In short, parents believed that both the music and art classes had a positive effect on their children's overall learning, motivation, and cultivation of interest in the arts.

\section{Discussion}

The purpose of this paper was to examine the beliefs of parents from low-income communities concerning the relationship between exposure to music and art and their children's interest in participating in the arts, their academic achievement, and a change in their behavior.

The overall results indicated that after eight months of training in music and art, parents reported seeing a direct influence of music on their children's interest in music and art, with both groups reporting and increased interest music, art and in reading, a secondary benefit. In addition, parents of children who had participated in the music program reported music as having a direct impact on their children's academic achievement. These results are in contrast to those of Custodero, Rebello, \& Xin (2002) (who found that middle-class parents did not feel that exposure to music would have a direct impact on their children's intellectual or academic ability. It should be noted, however, that for the children of middle-class families because music (classical music) and art are often a part of their everyday experience, parents may not view the arts as having a direct impact on their children's development even though they may be having an indirect impact. Whereas for children from low-income families, the effect may be perceived as more direct due to the lack of everyday exposure. This difference in exposure may account for the results reported in this study, which suggests that children from low-income families may be benefiting from having music and art as part of their overall curriculum in ways that middle-class children do not.

With respect to behavioral change, the findings from this study suggested participation in music or art leads to a positive change in children's behavior with parents reporting children listening more, attending more to objects and events in their immediate environment, and interacting with adults. These findings support the previous work by Hallam \& Price (1998), which demonstrated that exposing children to background music during class time often leads to positive changes in their overall behavior. However, unlike the Hallam \& Price study parents of children exposed to art in this study also reported a positive change in behavior, indicating that it might not be solely participation in music that is responsible for the change in behavior, but rather participation in an art form that functions to motivate and hold one's attention. 
In short, the findings from this study demonstrate that parents from low-income backgrounds believe exposure to music and art has a positive effect on their children's interest in the arts, academic achievement, and behavior. These findings are exciting because they provide an additional mechanism for working with families to help them support and enrich the learning environments of their children so that they can become partners in the art education of their children (Hanson, 2008).

\section{Educational Implications}

Politicians, social scientists, and educators are looking for credible and constructive ways to get parents involved in their children's education. While previous research findings have demonstrated that children exposed to music training perform better on specific academic tasks than their peers not exposed to music, to date, very few studies have explored what effect having parents involved in the music education of their children have on what their children learn. The findings from the present study suggest that because parents believe music and to some extent art has a positive effect on children's academic skills and in some cases behavior, parents who hold this belief may be more motivated, to not only expose their children to the arts outside of school, but also use music and art to enrich their children's reading, listening, and mathematical skills. Moreover, these results could prove valuable in motivating low-income parents to use creative ways to work with their children on those skills critical to their children's success in school. Future research should explore how parents' translate their beliefs into actually working with their children in the home setting.

\section{Acknowledgements}

The author would like to thank the $42^{\text {nd }}$ Street Fund for its partial support of the project. The author would also like to thank the school administrators, teachers, and parents who made this project possible.

\section{Conflicts of Interest}

The author declares no conflicts of interest regarding the publication of this paper.

\section{References}

British Psychological Society (BPS) (2013). Making Music May Improve Young Children's Behavior. Science Daily. http://www.sciencedaily.com/releases/2013/09/130905202851.htm

Brown, E. D., \& Sax, K. L. (2013). Arts Enrichment and Preschool Emotions for Low-Income Children at Risk. Early Childhood Research Quarterly, 28, 337-346. https://doi.org/10.1016/j.ecresq.2012.08.002

Brown, E. D., Benedett, B., \& Armistead, M. E. (2010). Arts Enrichment and School Readiness for Children at Risk. Early Childhood Research Quarterly, 25, 112-124. https://doi.org/10.1016/j.ecresq.2009.07.008 
Brown, E. D., Garnett, M. L., Velazquez-Martin, B. M., \& Mellor, T. J. (2018). The Art of Head Start: Intensive Arts Integration Associated with Advantage in School Readiness for Economically Disadvantaged Children. Early Childhood Research Quarterly, 45, 204-214. https://doi.org/10.1016/j.ecresq.2017.12.002

Costa-Giomi, E. (2004). Effects of Three Years of Piano Instruction on Children's Academic Achievement, School Performance and Self-Esteem. Psychology of Music, 32, 139-152. https://doi.org/10.1177/0305735604041491

Custodero, L. A., Rebello Britto, P., \& Xin, T. (2002). From Mozart to Motown, Lullabies to Love Songs: A Preliminary Report on the Parents' Use of Music with Infant Survey (PUMIS). Zero to Three, 23, 41-46.

Dai, D. Y., \& Schader, R. M. (2002). Decisions Regarding Music Training: Parental Beliefs and Values. Gifted Child Quarterly, 46, 135-144.

https://doi.org/10.1177/001698620204600206

Flores, R. (2006). The Effect of Arts Education on Urban Kindergarten Children's Academic Skills. Unpublished Manuscript, New York: Department of Psychology, Hunter College of the City University of New York.

Hallam, S. (2010). The Power of Music: Its Impact on the Intellectual, Social and Personal Development of Children and Young People. International Journal of Music Education, 28, 269-289. https://doi.org/10.1177/0255761410370658

Hallam, S., \& Price, J. (1998). Can the Use of Background Music Improve Behaviour and Academic Performance of Children with Emotional Difficulties? British Journal of Special Education, 25, 88-91. https://doi.org/10.1111/1467-8527.t01-1-00063

Hanson, L. (2008). Parents as Partners in Art Education Enrichment. YC Young Children, 63, 90-95. http://www.jstor.org/stable/42730341

Hurwitz, I., Wolff, P., Bortnick, B., \& Kokas, K. (1975). Nonmusical Effects of the Kodaly Music Curriculum in Primary Grade Children. Journal of Learning Disabilities, 8, 45-52. https://doi.org/10.1177/002221947500800310

Kantner, L., \& Hoffman, S. (1992). Parents' Perception of Their Children's Early Art Experience. Visual Arts Research, 18, 50-56. http://www.jstor.org/stable/20715768

Kirschner, S., \& Tomasello, M. (2010). Joint Music Making Promotes Prosocial Behavior in 4-Year-Old Children. Evolution and Human Behavior, 31, 354-364. https://doi.org/10.1016/j.evolhumbehav.2010.04.004

Lamb, S. J., \& Gregory, A. H. (1993). The Relationship between Music and Reading in Beginning Readers. Educational Psychology, 13, 19-26. https://doi.org/10.1080/0144341930130103

National Endowment of the Arts (2011). The Arts and Human Development: Framing a National Research Agenda for the Arts, Lifelong Learning, and Individual Well-Being. Washington DC: National Endowment for the Arts. https://www.arts.gov/publications/arts-and-human-development-framing-national-res earch-agenda-arts-lifelong-learning-and

National Endowment of the Arts (2015). The Arts in Early Childhood: Social and Emotional Benefits of Arts Participation. Literature Review and Gap-Analysis (2000-2015). Washington DC.

https://www.arts.gov/publications/arts-early-childhood-social-and-emotional-benefitsarts-participation

Rauscher, F. (2003). Can Music Instruction Affect Children's Cognitive Development? http://ericeece.org

Rauscher, F. H., \& Zupan, M. A. (2000). Classroom Keyboard Instruction Improves Kin- 
dergarten Children's Spatial Temporal Performance: A Field Experiment. Early Childhood Research Quarterly, 15, 215-228. https://doi.org/10.1016/S0885-2006(00)00050-8

Rauscher, F. H., Robinson, K. D., \& Jens, J. (1998). Improved Maze Learning through Early Music Exposure in Rats. Neurological Research, 20, 427-432. https://doi.org/10.1080/01616412.1998.11740543

Rauscher, F. H., Shaw, G. L., Levine, Ky, K. N., \& Wright, E. L. (1994). Music and Spatial Task Performance: A Causal Relationship. The 102nd Annual Meeting of the American Psychological Association, Los Angeles, CA.

Vaughn, K. (2000). Music and Mathematics: Modest Support for the Oft-Claimed Relationship. Journal of Aesthetic Education, 34, 149-166. https://doi.org/10.2307/3333641 